\title{
Erratum to: Prognostic impact of CXCL16 and CXCR6 in non-small cell lung cancer: combined high CXCL16 expression in tumor stroma and cancer cells yields improved survival
}

Sigurd M. Hald ${ }^{1 *}$, Yury Kiselev ${ }^{3,6}$, Samer Al-Saad ${ }^{3,5}$, Elin Richardsen ${ }^{3,5}$, Charles Johannessen ${ }^{3}$, Marte Eilertsen? Thomas K. Kilvaer ${ }^{2}$, Khalid Al-Shibli, ${ }^{3,4}$, Sigve Andersen ${ }^{1,2}$, Lill-Tove Busund ${ }^{3,5}$, Roy M. Bremnes ${ }^{1,2}$ and Tom Donnem ${ }^{1,2}$

\section{Erratum}

After publication of the original article [1], the author noticed that there are some error with Table 2 and Table 3. Please see the correct Tables below. We apologize for any inconvenience caused.

\footnotetext{
Author details

'Department of Clinical Medicine, UiT The Arctic University of Norway, 9037

Tromso, Norway. ${ }^{2}$ Department of Oncology, University Hospital of North Norway, Tromso, Norway. ${ }^{3}$ Department of Medical Biology, UiT The Arctic University of Norway, Tromso, Norway. ${ }^{4}$ Department of Pathology, Nordland Hospital, Bodo, Norway. ${ }^{5}$ Department of Clinical Pathology, UniversityHospital of North Norway, Tromso, Norway. ${ }^{6}$ Department of Pharmacy, UiT The Arctic University of Norway, Tromso, Norway.
}

Received: 14 November 2016 Accepted: 14 November 2016

Published online: 24 November 2016

\section{References}

1. Hald SM, et al. Prognostic impact of CXCL16 and CXCR6 in non-small cell lung cancer: combined high CXCL16 expression in tumor stroma and cancer cells yields improved survival. BMC Cancer. 2015;15:441. doi:10.1186/ s12885-015-1446-z.

\footnotetext{
*Correspondence: sigurd.hald@uit.no

'Department of Clinical Medicine, UiT The Arctic University of Norway, 9037
} Tromso, Norway 
Table 2 CXCL16 and CXCR6 expression as predictors of diseasespecific survival in 335 NSCLC patients

\begin{tabular}{|c|c|c|c|c|}
\hline Characteristics & $\begin{array}{l}\text { Patients, } \\
\text { N (\%) }\end{array}$ & $\begin{array}{l}\text { Median survival } \\
\text { (months) }\end{array}$ & $\begin{array}{l}\text { 5-year } \\
\text { survival (\%) }\end{array}$ & $P$ \\
\hline \multicolumn{5}{|l|}{ CXCL16 } \\
\hline \multicolumn{4}{|l|}{ Cancer cells } & .080 \\
\hline High & $48(14)$ & NR & 67 & \\
\hline Low & $227(68)$ & 98 & 56 & \\
\hline Missing & $60(18)$ & & & \\
\hline \multicolumn{4}{|l|}{ Stromal cells } & .016 \\
\hline High & $258(77)$ & 189 & 62 & \\
\hline Low & $43(13)$ & 57 & 48 & \\
\hline Missing & $34(10)$ & & & \\
\hline \multicolumn{5}{|l|}{ CXCR6 } \\
\hline \multicolumn{4}{|l|}{ Cancer cells } & .093 \\
\hline High & $41(12)$ & 190 & 73 & \\
\hline Low & $245(73)$ & 122 & 55 & \\
\hline Missing & $49(15)$ & & & \\
\hline \multicolumn{5}{|l|}{ CXCL16 } \\
\hline \multicolumn{4}{|l|}{$\begin{array}{l}\text { Cancer cells + stromal } \\
\text { cells combined }\end{array}$} & .016 \\
\hline High/High & $43(13)$ & NR & 71 & \\
\hline High/Low & $182(54)$ & 190 & 58 & \\
\hline Low/Low & $41(12)$ & 47 & 48 & \\
\hline Missing & $69(21)$ & & & \\
\hline
\end{tabular}

NR, not reached; NCSLC, non-small cell lung cancer. Bold values indicate $\mathrm{p}<0.05$
Table 3 Results of multivariate Cox regression analyses for clinicopathological factors and CXCL16 in stromal cells (model 1) and co-expression of CXCL16 in cancer and stromal cells (model 2*)

\begin{tabular}{llll}
\hline Factor & $H R$ & Cl 95\% & $P$ \\
\hline T-status & & & $<0.00 \mathbf{1}^{\dagger}$
\end{tabular}

T1

$\mathrm{T} 2$

T3

1.00

1.60

$(0.97-2.64)$

0.065

$\mathrm{N}$-status

$3.80 \quad(2.13-6.77)$

$<0.001$

NO

$<0.001^{\dagger}$

N1

1.00

N2

2.01

(1.30-3.11)

0.002

3.08

(1.74-5.44)

$<0.001$

Differentiation

$0.009^{\dagger}$

Well

Moderate

1.00

Poor

(0.63-2.20)

0.618

1.17

(1.12-3.85)

0.020

Performance status

$0.040^{\dagger}$

ECOG 0

1.00

ECOG 1

(1.02-2.26)

0.040

ECOG 2

(0.94-4.91)

0.069

Vascular infiltration

No

Yes

1.00

1.70

(1.01-2.87)

0.046

Histology

$<0.001^{\dagger}$

Squamous carcinoma

1.00

Adenocarcinoma

2.23

$(1.48-3.35)$

$<0.001$

Large cell carcinoma

0.80

$(0.39-1.66)$

0.555

CXC16 stromal cells

$\begin{array}{llll}\text { Low } & 1 & & \\ \text { High } & 0.55 & (0.35-0.87) & \mathbf{0 . 0 1 1} \\ \text { CXCL16 cancer and stromal cells* } & & & \mathbf{0 . 0 3 1}^{+} \\ \text {Low/Low } & 1.00 & & \\ \text { Low/High + High/Low } & 0.57 & (0.35-0.93) & \mathbf{0 . 0 2 3} \\ \text { High/High } & 0.42 & (0.20-0.88) & \mathbf{0 . 0 2 2}\end{array}$

${ }^{\dagger}$ Overall significance as prognostic marker. $\mathrm{HR}$, Hazard ratio. Bold values indicate $\mathrm{p}<0.05$ 